\title{
Analyzing the Influence of Selected Talent Management Practices on Employee Discretionary Work Behaviours in Organizations
}

\author{
Samuel Mwachiro Mwawasi \\ Department of Business Management and Economics, Pwani University, Kilifi, Kenya
}

Email address:

samchiros@yahoo.com

\section{To cite this article:}

Samuel Mwachiro Mwawasi. Analyzing the Influence of Selected Talent Management Practices on Employee Discretionary Work Behaviours in Organizations. Journal of Human Resource Management. Vol. 9, No. 3, 2021, pp. 64-68. doi: 10.11648/j.jhrm.20210903.12

Received: August 30, 2020; Accepted: April 30, 2021; Published: July 19, 2021

\begin{abstract}
Talent management is significant in every organization if it is to achieve sustainable competitive advantage. Despite this knowledge critical talents remain scarce in many organizations which impair their growth and competitiveness. In many organizations, managers still maintain agency relationships with employees based on the assumption that employment contracts and rewards are sufficient to induce employees to contribute their best efforts towards organizational success. In many instances they ignore the value of providing environments where talents can thrive and be developed. This has made organizations unable to achieve their full potential. Available literature suggests that a range of managerial practices can be used to increase the likelihood of employees in applying their skills beyond the contractual prescriptions. It is on this basis that the paper endeavors to find out the influence of talent management practices and employee discretionary behaviour in organizations, main discretionary behaviours influenced by such practices and the relationship between managerial practices and employee discretionary behaviours. These objectives are clarified by literature from secondary sources that have demonstrated great consensus on the need for Managers to develop innovative talent management practices. These will lead to the emergence of new cultures based on teamwork, collaboration and innovation. Managers can also develop Innovative recruitment and selection processes that can lead to quick identification of highly talented employees and fit them in high performance groups to facilitate risk taking and innovation. This can be complemented by developing a positive psychological contract that can be influenced through rewards and career growth. These activities should be complemented with effective employee retention practices coupled with ethical and socially responsible leadership, to influence employee discretionary behaviours.
\end{abstract}

Keywords: Talent, Employee's Natural Abilities and Skills, Coaching, Personalized Employee Development and Guidance, Discretionary Behavior, Unrewarded Volitional Actions and Behaviours

\section{Introduction}

Talent management is increasingly gaining importance in modern organizations. A study conducted by KPMG in 2012 targeting 418 business executives reveals that majority of them view talent management as being useful in enabling the organization to achieve competitive advantage [1]. Another study conducted by PWC in 2017 targeting CEOs, indicated that many organizations are faced with scarcity of essential skills and capabilities which threatens their growth and survival [2]. Other writers have focused majorly on the benefits of talent management to the achievement of organizational goals $[3,4,1]$. There is general consensus in existing literature about the benefits of talent management to the organization. However, there is need for more information about the different innovative talent management techniques to be used to deliver maximum benefits to organizations and how these techniques can lead to effective employee discretionary actions in organizations.

\subsection{Objectives of the Study}

1) To find out Selected innovative talent management practices that can influence employee discretionary behaviours in organizations. 
2) To find out the main employee behaviors influenced by managerial practices.

3) To identify the relationship between Managerial Practices and employee discretionary behaviours.

\subsection{Materials and Methods}

The study relies on various secondary data sources such as books and journals. Extensive literature review is carried out to establish the relationships that exist between the variables under investigation. Multidisciplinary research approach has been used to draw Conclusions based on analysis of literature.

\subsection{Theoretical Framework}

To better understand the factors influencing employee's discretionary behaviour, the paper draws from the Social Exchange Theory proposed by George Homans, 1958.

The Social Exchange Theory

This theory explains how individuals go about making decisions about what they are willing to give up in terms of an exchange involving costs and rewards. Costs include the time that is spent to build skills or relationships, time spent to innovate, freedom, money, loss of social relationships, risk of failure, lost opportunity to spend time in more rewarding relationships and loss of leisure time, energy spent on a task and the skills applied on the task, as well as punishment imposed for failure to accomplish a task, Rewards include love, services, goods, opportunity for social support, feeling appreciated, opportunities for career advancement, participation in goal setting and decision making, feeling of pleasure and satisfaction, and the view that the individual is respected and socially acceptable. The individual's decision on whether to pursue or terminate a relationship will be based on his or her assessment of the relationship between costs and rewards. According to this theory, social behaviours often involve social exchanges where individuals are motivated to attain some valued reward for which they must forfeit something of value i.e., cost. For the relationship to be sustained, the rewards should be greater than the costs. Costs are incurred due to the expectations of a reward. In a formal work organization, individuals view their relationship with the employer in terms of an exchange whose outcome is the attainment of goals in exchange for a valued reward. In a work environment, the Social exchange Theory is useful in explaining the following individual behaviors which are outcomes of their decisions on whether to pursue a certain course of action based on their evaluation of costs and rewards.

\section{i) Goal Setting Behaviours}

Goal setting at individual or team level will be easier if individuals believe goal attainment will be valued and appreciated by the management. For this to happen, managers need to develop a working environment based on trust. This is the only way employees will invest their time, energy, skills and other resources towards goal accomplishment.

\section{ii) Risk Taking Behaviours}

Employees will take risks because they have a genuine desire to see the organization thrive and grow. However whether they will take risks or not is to a great extent influenced by how managers handle failures and achievements associated with risk taking behaviors. In cases where failure is taken as a learning opportunity employees feel encouraged to innovate, develop new methods of work, new products, investing in new relationships and participate in individual learning and development initiatives. Learning and development creates opportunities for knowledge creation and sharing. When failure is punished and success is not shared with the employees, they are discouraged from risk taking activities.

\section{iii) Cooperation}

Individuals will be more willing to cooperate with their peers and management if they believe that the outcomes of such cooperative relationships is the attainment of goals which lead to the attainment of a valued reward whether financial or non financial. In their relationship with the management employees will share knowledge and ideas if they believe that the management of the organization is flexible to accommodate ideas and suggestions from them and that they will provide opportunities and resources for their implementation. At team level, employees feel much more empowered if they are given responsibility to manage and lead their teams towards goal attainment. This will be useful as it provides individuals to exercise discretion on team activities such as team goal setting, planning, monitoring and control of member behaviors.

iv) Learning and Development

When individuals invest their time, money and other resources, they do it with a genuine and legitimate expectation that they will eventually be rewarded. Rewards include provision of opportunities to acquire and apply new knowledge and skills, to introduce new methods of work, provision of opportunities to share knowledge and other learned experiences for the benefit of the organization. When such opportunities exist, employees will be more willing to learn and be developed either through managerial initiatives such as coaching and mentorship or through self designed learning initiatives.

\section{Results and Discussions}

The role of managers in talent management cannot be overemphasized. For an organization to improve productivity and achieve competitive advantage, it needs to develop new innovative approaches for managing talented employees. Productivity gains can be sustained if employees are given an opportunity to carry out activities beyond their normal call of duty. Some of the approaches that can benefit an organization include the following:

\subsection{Developing the Right Organizational Culture}

For employees to fully apply their skills and knowledge in the work situation, managers must create a culture that values 
teamwork, innovation, coaching, collaboration, knowledge development and sharing. This culture must be based on trust, [3, 5-11]. Such a culture will encourage development of cooperative relationships based on trust and mutual interdependence which are useful in providing opportunities for problem solving and knowledge sharing.

\subsection{Developing Responsive Recruitment and Selection Systems}

For effective utilization of talents and to have a higher chance of employee fit with organizations business strategies, the process of procuring human resources should be more focused on developing systems to capture high caliber employees with competencies and who are willing to make a contribution to the organization. It is important to recruit and select employees who are willing to be developed and ready to work in high performance groups. These employees should also be willing to take risks and innovate based on their capabilities and potential, [12-14, 3-4, 1].

\subsection{Developing a Positive Psychological Contract}

This will make employees take individual responsibility for their career growth because they feel valued and develop expectations that they will be rewarded for what they do and achieve. [12]

\subsection{Developing Innovative Reward Systems}

Rewards have a powerful influence on employee's performance. Within the talent management framework, managers must develop reward systems which differentiate performance of individuals and groups and which will make employees feel recognized, appreciated and valued. Such rewards will improve productivity, commitment and overall performance of the organization. Flexible reward systems will make employees more willing to be developed and increases individual responsibility in career planning and management $[15,7,9,16,13,14,1]$.

\subsection{Employee Development and Retention Strategies}

Effective talent management requires managers to develop new systems for developing employees as to enable them to utilize their skills, capabilities and potential. This is important in minimizing employee turnover. Employee development activities should move away from training and focus more on coaching and mentorship, [17, 6, 16, 14, 4]. Retention of employees can be enhanced if employees view the organization as good employer, if they have opportunities for learning and career advancement, and if they are properly matched with their roles. In addition employees want to see that their skills are recognized and rewarded. They also want to feel respected and be sure that what they are doing will lead to achievement of a valued goal. They also need to be given the opportunity to flexibly utilize their skills $[12,18,19$, $16,13,14,3,4]$.

\subsection{Development of New Leadership Skills}

The role of leadership in talent management has been discussed by [1], who suggest that employees will be more willing to utilize their skills in organizations they perceive to be socially responsible. Leadership requires the establishment of new structures which facilitate quick decision making and the use of flexible communication systems developing skills, executing work and giving feedback, [20, 7, 13, 14]. Others focus on process improvement and development of inter-organizational networks to create new ways of doing things $[6,5,10]$.

Interaction Between Managerial Practices and Employee Discretionary Behaviours

There are several individual factors which can be influenced by managerial practices to induce discretionary behaviors of employees within the work context. Discretionary behaviors refers to the employee behaviour that is not directly or explicitly recognized by the formal reward system, and in the aggregate promotes the efficient and effective functioning of the organization, [21]. Discretionary behaviors contribute to effective task performance, maintainance of organizational social and cooperative systems, improved creativity and organizational Growth.

\section{i) Employee Attitudes}

Employees are more likely to exhibit discretionary work behaviors if they believe the managers value what they know, if they believe have the required capabilities to cope with the work situation, and if they believe that managers will always honor their commitments in terms of providing opportunities to autonomously apply skills, opportunities for career growth and rewards for doing things differently such as by introducing individual and team rewards. These actions positively influence the employee attitude, $[6,16,21,13,3$, 14], hence making them to engage in discretionary work behaviors. Positive employee attitudes are beneficial to organizations in terms of enhancing employee job satisfaction, improved relationships among co-workers and groups, and improve means of interaction and better use of technology.

ii) Employee Commitment

Employee commitment is the employees psychological bond to the organization, $[6,9,12,18,15,21,14,3,1,4]$. Employee commitment is a reliable predictor of discretionary effort to the extent that managers maintain a positive psychological contract; introduce work systems based on teamwork, autonomy and flexibility. This culture should encourages regular information sharing, continuous knowledge acquisition and use in organizations. Additionally, employee commitment can be enhanced if the organization adopts a culture of excellence and gives room for employees to experiment innovate and grow within the organization. This can be reinforced by introduction of differentiated individual and team rewards system which demonstrates the management's value and commitment to knowledge, experience and results. The organization should 
also position itself as a good employer by living up to its values and acting ethically and in a socially responsible manner. These managerial actions make employees develop a feeling of self worth, being trusted which enhances their self efficacy. This leads to the development of supportive and cooperative relationships between employees and management as well as those among employees in work groups. This makes the employees more likely to engage in discretionary actions.

\section{iii) Employee Engagement}

This is the commitment of employees to the organization and its values and their desire to help out their colleagues. As cites in [16] Employee engagement has direct benefits to the organization such as improved productivity and performance, production of better quality goods and services, reduced turnover, reduced absenteeism and conflicts and enhanced cooperation. Employee engagement can be enhanced if the organization develops a positive psychological contract and managers demonstrate that they value employee's skills and what they do through development of cooperative and supportive work relationships which encourage knowledge sharing. For employees to be fully engaged, they need to have a clear idea how their efforts will contribute the goals valued by the organization and they need to be assured that they have a future in the organization. [12, 15, 6, 7, 9, 4, 19, 14]. These managerial actions can go a long way in encouraging employees to engage in discretionary work behaviours for their own gain and organizational benefit.

\section{iv) Willingness to Learn}

Employees will be more willing to cooperate if they believe that the organization is committed to providing continuous learning opportunities and is willing to allocate resources for purposes of improving individual and team performance, for improving their chances of career growth and opportunities to apply their skills in the work situation. Discretionary work behaviours will be most noticeable among workers who feel that application of what they have learned will be respected and rewarded by management as part of the process of introducing organizational change, [5, $6,13]$.

\section{Conclusions and Recommendations}

Talent management has gained significance in organizations in modern times. Effective talent management delivers value to the organization through improving its performance productivity and improved customer service. Additionally; good talent management practices positively influence employee attitudes towards their work and the organization. This is particularly important in improving employee cooperation, willingness to take risk and innovate, improving problem solving and their desire to learn. Sustainable organizational performance can be attained if mangers adopt leadership and managerial approaches that positively influence employees to engage in discretionary work practices.

\section{Acknowledgements}

I wish to acknowledge the Pwani University library staff for providing me with physical resources such as books and other electronic materials that contributed to the success in writing of this paper. Additionally, I acknowledge that in writing the paper, private funds were used and there is no conflict of interest that influenced the motive to write it but the desire to advance academic and managerial knowledge and understanding. Finally, the ideas shared in this paper are the author's and do not in any way reflect the official position of the affiliated institution.

\section{References}

[1] Anthony McDonnell, David G. Collings, Kamel Mellahi and Randall Schuller, 2017. Talent Management: A Systematic Review and Future Prospects. European Journal of International Management, Volume 11 (1), pp 86128.smlr.rutgers.edu/sites/default/files/images/literature_revie w_of_tm_in_ejim_jan_2017_Mcdonnel_et_al.pdf.Accessed on $16 / 04 / 20,03: 13$ PM.

[2] Eva Gallardo-Gallardo, Marian Thunnissen and Hugh Scullion, 2019. Talent Management: Context Matters. The International Journal of Human Resource Management 31 (4), pg 457-473.

[3] Thomas H. Davenport and Lawrence Prusak, 2000. Working Knowledge, Havard Business School Press, USA.

[4] Eva Bostjancic and Zala Slana, 2018. The Role of Talent Management. Comparing Medium-Sized and Large Companies. Major Challenges in Attracting and Retaining Employees. Front. psychol., 19 September 2018/https://doi.org/10.3389/fpsyg.201801750. Accessed on 16/04/20, 2:30 PM. https://doi.org/10.1080/09585192.2019.1642645. Accessed on 16/04/20, 02:40 PM.

[5] Awad and Ghaziri, 2010. Knowledge Management, 2nd Ed., International Technology Group, USA.

[6] Laurie J. Mullins, 2010. Management and Organizational Behaviour, 9th Ed. Pearson Education, UK.

[7] Mellissa A. Schilling, 2010. Strategic Management of Technological Innovation, McGraw-Hill, NY.

[8] Anne-Wil Harzing and Ashley H. Pinnington. 2011. International Human Resource Management, 3rd Ed. Sage publications, London, UK.

[9] Peter F. Drucker, 2011. The Practice of Mangement, Routledge, NY, USA. Pdfs. Semantic scholar.org/f2a5/dee7773f3b63757 dd3a63bf232e25ddc59fb.pdf.Accessed on 17/04/20 at 09.00 Pm.

[10] Richard L. Daft, 2012. New Era Management, 10th, Ed. South-Western, Cengage Learning.

[11] Joe Tidd and John Bessant, 2009. Managing Innovation. Integrating Technological, Market and Organizational Change, John Wiley\&Sons, UK.

[12] Phillip Lewis, Adrian Thornhill and Mark Saunders, 2003. Employee Relations: Understanding the Employment Relationship, Pearson Education Limited, UK. 
[13] Prathigadapa and Gavanapavarapu, 2014. Talent Management: A Critical Review. Journal of Business and Management, 16 (9) pp 50-54.

[14] Agnes Chemaiyo Kurgat, 2016. Talent Management and its Importance for Today's Organizations in Kenyan Perspective; A Critical Review. International Journal of Advances in Management and Economics, 5 (5) 01-08. Pp 72-214. C:/users/ADMIN/Downloads/72-214-PB.pbf.Accessed on $17 / 04 / 20$ at 08.07 PM.

[15] Kimiz Dalkir, 2005. Knowledge Management in Theory and Practice. Elsevier Inc, Oxford, UK.

[16] Paul Evans, Vladimir Pucik and Ingmar Bjorkman, 2011. Talent Management. The Global Challenge. International Human Resource Management. $2^{\text {nd }}$ Ed, McGraw-Hill, NY, USA.

[17] Harvard Business School, 2004, Coaching and Mentoring, Havard Business School Publishing Corporation.
[18] Jack J. Phillips and Adele O. Connel, 2003. Managing retention. A Strategic Accountability Approach, Elsevier, Oxford, UK.

[19] Vlad Valman and David G. Collins, 2013. Talent Management: Advancing the Field. Journal of Human Resource Management, 24 (9) pp 1734-1743. http://doi.org/10.1080/09585192.2013.777544. Accessed on $17 / 4 / 20,08.30 \mathrm{pm}$.

[20] Donald Hislop, 2009. Knowledge Management in Organizations. A Critical Introduction, 2nd Ed. Oxford University Press, UK.

[21] Ibrahim Duyar and Anthony H. Nomore, 2012. Discretionary Behaviour and Performance in Educational Organizations. The Missing Link in Educational Leadership and Management.

Emerald.com/insight/content/doi/10.1108/51479-

3660(2012)0000013005/full/html. Accessed on 18/04/20 at 4:50 pm. 